\title{
PRODUCTIVITY IMPROVEMENT THROUGH MONITORING OF HUMAN RESOURCES COMPETENCE LEVEL
}

\author{
OtTo, T.; RiIVES, J. \& LOUN, K.
}

Abstract: The proposed model is capable of monitoring the quality and quantity of technological resources in machine-building enterprises of the network. Factors as equipment, work organization tools, and human resources were viewed and taken into consideration all together and in balance. Influence of human resources can be evaluated successfully when using proper taxonomy and expert estimations. The described methodology of human resources development has been thoroughly tested in different institutions.

Key words: Productivity, Human resource management, Advisory system, Database
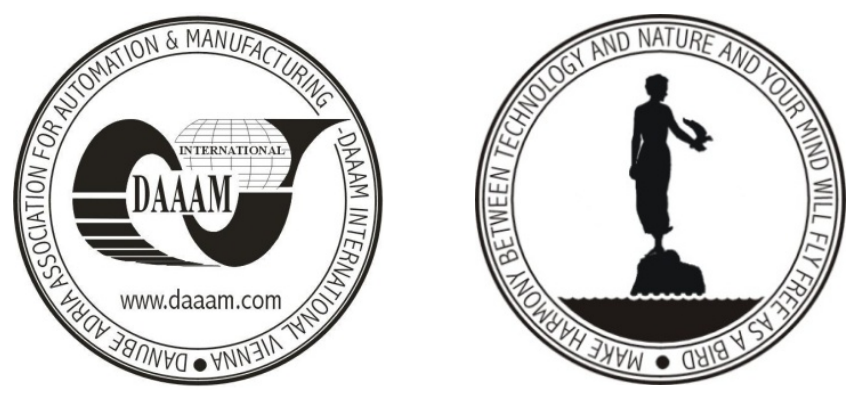

Authors' data: Dr. Assoc. Prof. Otto, T[auno]*; Riives, J[yri]*; consultant/project manager Loun, K[aia]**, *Tallinn University of Technology, Sõpruse 186-7, 13424, Tallinn, EE, **J.R.Technoconsult, Ravi 16-10, 10138, Tallinn, EE, tauno.otto@gmail.com, jyri@eestitalleks.ee,kaia.loun@mail.ee

This Publication has to be referred as: Otto, T[auno]; Riives, J[yri] \& Loun, K[aia] (2008). Productivity Improvement through Monitoring of Human Resources Competence Level, Chapter 48 in DAAAM International Scientific Book 2008, pp. 565-576, B. Katalinic (Ed.), Published by DAAAM International, ISBN 978-3901509-66-7, ISSN 1726-9687, Vienna, Austria

DOI: $10.2507 /$ daaam.scibook.2008.48 